Vol 8, No 2 (2021), Desember; p.231-241 ;https://e-journal.stie-aub.ac.id/index.php/excellent

Achievement Of Master Of Science And Work Discipline In Increasing Job Satisfaction And Employees Performance In Sragen District Sragen Regency

\title{
Pencapaian Penguasaan Iptek Dan Disiplin Kerja Dalam Meningkatkan Kepuasan Kerja Dan Kinerja Pegawai Di Kecamatan Sragen Kabupaten Sragen
}

\author{
Antik Indiastri ${ }^{1)}$, Septiana Novita Dewi ${ }^{2)}$ \\ antikindiastri@ rocketmail.com, Septianadewi25@yahoo.co.id \\ Mahasiswa Magister Manajemen STIE-AUB Surakarta, Dosen Magister Manajemen STIE-AUB Surakarta
}

\begin{abstract}
ABSTRAK
Penelitian ini bertujuan untuk mengetahui dan membuktikan secara empiris tentang pencapaian penguasaan iptek dan disiplin kerja dalam mencapai kepuasan kerja terhadap kinerja pegawai Kecamatan Sragen Kabupaten Sragen. Metode analisis yang digunakan adalah analisis jalur. Dengan jumlah populasi sebanyak 64 responden yang diambil berdasarkan metode sensus. Hasil penelitian menunjukkan penguasaan iptek berpengaruh tidak signifikan terhadap kepuasan kerja. Disiplin kerja berpengaruh signifikan terhadap kepuasan kerja. Penguasaan iptek berpengaruh signifikan terhadap kinerja pegawai. Disiplin kerja berpengaruh tidak signifikan terhadap kinerja pegawai. Kepuasan kerja berpengaruh signifikan terhadap kinerja pegawai. Hasil uji $\mathrm{F}$ dapat disimpulkan secara bersama-sama penguasaan iptek, disiplin kerja dan kepuasan kerja berpengaruh signifikan terhadap kinerja pegawai Kecamatan Sragen Kabupaten Sragen. Nilai $\mathrm{R}^{2}$ total sebesar 0,989 dapat diartikan variasi kinerja pegawai di Kecamatan Sragen Kabupaten Sragen dijelaskan oleh variabel penguasaan iptek, disiplin kerja dan kepuasan kerja, sebesar 98,9\%. Hasil analisis jalur diketahui jalur tidak langsung disiplin kerja terhadap kinerja melalui kepuasan kerja, merupakan jalur yang dominan atau efektif untuk meningkatkan kinerja pegawai di Kecamatan Sragen Kabupaten Sragen
\end{abstract}

Kata Kunci : Penguasaan Iptek, Disiplin Kerja, Kepuasan Kerja, Kinerja Pegawai

\begin{abstract}
This study aims to find out and prove empirically about the achievement of mastery of science and technology and work discipline in achieving job satisfaction on the performance of employees in Sragen District, Sragen Regency. The analytical method used is path analysis. With a population of 64 respondents who were taken based on the census method. The results showed that mastery of science and technology had no significant effect on job satisfaction. Work discipline has a significant effect on job satisfaction. Mastery of science and technology has a significant effect on employee performance. Work discipline has no significant effect on employee performance. Job satisfaction has a significant effect on employee performance. The results of the $\mathrm{F}$ test can be concluded that simultaneously mastery of science and technology, work discipline and job satisfaction have a significant effect on the performance of employees in Sragen District, Sragen Regency. The total R2 value of 0.989 can be interpreted as the variation of employee performance in Sragen District, Sragen Regency explained by the variables of science and technology mastery, work discipline and job satisfaction, amounting to $98.9 \%$. The result of path analysis shows that the indirect path of work discipline on performance through job satisfaction is the dominant or effective path to improve employee performance in Sragen District, Sragen Regency.
\end{abstract}

Keywords : Mastery of Science and Technology, Work Discipline, Job Satisfaction, Employee Performance 


\section{PENDAHULUAN}

Perkembangan kehidupan dan teknologi pada saat ini dirasakan semakin cepat dan menuntut adanya perubahan di berbagai sektor. Penguasaan IPTEK mutlak dibutuhkan guna menunjang perubahan dan perkembangan tersebut. Dampak tersebut secara otomatis berimbas kepada dunia usaha maupun dunia industri. Penguasaan teknologi industri yang lebih maju dibutuhkan agar dapat menciptakan produk dan kualitas yang lebih baik. Sumber Daya Manusia (SDM) sebagai tenaga yang meguasai peralatan teknologi juga dintuntut untuk semakin handal dalam menjalankan segala macam teknologi yang lebih maju. Seringkali, kualitas Sumber Daya Manusia dapat menjadi tolok ukur seberapa besar kualitas dari produk yang dihasilkan. Untuk itu pelatihan untuk meningkatkan kemampuan Sumber daya Manusia sangat diperlukan sehingga menciptakan kesejahteraan yang lebih baik. Sumber daya manusia merupakan salah satu unsur atau bagian investasi terbesar dari suatu organisasi. Oleh karena itu banyak sekali organisasi yang mulai secara serius membangun dan mengembangkan sumber daya manusianya. Nilai dari sumber daya manusia akan tampak jelas ketika suatu organisasi mulai kurang berkembang. Sumber daya manusia (SDM) yang berkualitas adalah sumber daya manusia yang memiliki kompetensi tinggi dan ketrampilan yang dapat memajukan organisasi.

Upaya-upaya untuk meningkatkan kinerja pegawai merupakan tantangan manajemen yang paling serius maka dari itu kinerja seseorang dapat di pengaruhi oleh faktor penguasaan iptek, disiplin kerja dan kepuasan kerja untuk mendorong para pegawai untuk mempunyai hasil pekerjaan yang baik serta jumlah pekerjaan yang standar. Menurut Sedarmayanti, (2014) kinerja pegawai merupakan hasil atau prestasi kerja pegawai yang dinilai dari segi kualitas maupun kuantitas berdasarkan standar kerja yang ditentukan oleh pihak organisasi. Kinerja yang baik adalah kinerja yang optimal, yaitu kinerja yang sesuai standar organisasi dan mendukung tercapainya tujuan organisasi. Peningkatan kinerja pegawai akan membawa kemajuan bagi organisasi untuk dapat bertahan dalam suatu persaingan lingkungan bisnis yang tidak stabil.

Upaya mewujudkan pemerintahan yang baik (Good Governance), bersih dan mampu memberikan pelayanan terbaik kepada masyarakat, maka pemerintah Kecamatan Sragen bertekad meningkatkan mutu Pelayanan publik (Public service) hal ini merupakan implementasi pelimpahan sebagian kewenangan dari Bupati Sragen dengan SK. No. 503/186-03/2001, tgl.16-82001. Kecamatan Sragen Kabupaten Sragen memiliki visi "Bersama menuju Sragen yang sejahtera, mandiri dan berkepribadian". Dalam rangka mengupayakan perwujudan visi di atas, maka misi yang harus dilaksanakan oleh Kecamatan Sragen beserta seluruh masyarakat yaitu:

1. Mewujudkan pemerintah desa yang bersih transparan dan akuntabel melalui kebersamaan pemerintah desa dan peran serta lembaga-lembaga pemerintahan desa dan masyarakat pada umumnya

2. Pembangunan menyeluruh baik fisik dan non fisik serta jiwa dan raga untuk mencapai kecamatan Sragen yang sejahtera lahir dan batin

3. Membangun ekonomi perdesaan yang kuat dengan menggali dan mengoptimalkan potensi desa

4. Membentuk sumber daya manusia yang berkualitas dengan memberdayakan peran serta masyarakat

5. Memberi pelayanan yang prima dan optimal kepada masyarakat

Perilaku seorang pemimpin dalam hal ini adalah pimpinan Kecamatan Sragen Kabupaten Sragen dalam menggerakkan dan memberdayakan juga akan mempengaruhi kinerja pegawai. Wursanto (2015:200) menyatakan bahwa perilaku pemimpin memiliki dampak yang signifikan terhadap sikap, perilaku dan kinerja bawahan. Efektivitas seorang pemimpin akan sangat dipengaruhi oleh karakteristik bawahannya. Perilaku pemimpin pada dasarnya terkait dengan proses pertukaran yang terjadi antara pemimpin dan bawahnnya. Pemimpin dikatakan gagal, apabila tidak dapat memunculkan gaya penguasaan iptek, menggerakkan dan memuaskan pegawai 
pada suatu pekerjaan dan lingkungan tertentu. Selain itu tugas pemimpin adalah mendorong bawahan agar memiliki kompetensi melalui pelatihan-pelatihan dan dukungan, serta mengkondisikan bawahan memiliki kesempatan untuk tumbuh dan berkembang dalam mengantisipasi setiap tantangan dan peluang untuk bekerja secara mandiri.

Hasil penelitian Pandapotan, (2019), Wulandari, (2016), menunjukkan terdapat pengaruh yang positif penguasaan iptek terhadap kepuasan kerja, sedangkan penelitian Laura dan Hidayat, (2016), menunjukkan terdapat pengaruh yang tidak signifikan penguasaan iptek terhadap kepuasan kerja. Lebih lanjut hasil penelitian Susanto, (2019) Gama, et.,al (2017), Yunanato (2016), menunjukkan terdapat pengaruh yang signifikan penguasaan iptek terhadap kinerja pegawai, sedangkan penelitian Pandapotan, Chen dan Colin (2015) menunjukkan terdapat pengaruh yang tidak signifikan penguasaan iptek terhadap kinerja pegawai. Berdasarkan perbedaan hasil penelitian (research gab) hasil penelitian, maka penelitian ini menganalisis pengaruh penguasaan IPTEK terhadap kepuasan dan kinerja pegawai.

Penguasaan iptek merupakan hal yang sangat penting dalam manajerial, karena penguasaan iptek maka proses manajemen akan berjalan dengan baik dan pegawai akan bergairah dalam melakukan tugasnya (Hasibuan, 2017:294) Penguasaan iptek yang andal sangat dibutuhkan organisasi demi tercapainya tujuan, karena penguasaan iptek adalah suatu proses dalam mempengaruhi kegiatan seseorang atau kelompok dalam usaha pencapaian tujuan. Keberhasilan dalam pencapaian sasaran kelompok (organisasi) sangat bergantung pada peran pemimpinnya. Semakin pandai pemimpin melaksanakan peannya, tentunya semakin cepat tujuan organisasi tersebut dapat dicapai. Penerapan penguasaan iptek antara pemimpin yang satu dengan yang lainnya berbeda, tergantung pada perilaku pemimpin yang diterapkan. Tanggung jawab sari seseorang pemimpin adalah mendorong pegawai kearah pencapaian tujuan-tujuan yang bermanfaat. Pegawai perlu merasakan bahwa mereka memiliki sesuatu yang bermanfaat yang harus dilakukan dan sesuatu yang dapat dilakukan dengan sumber-sumber daya yang ada dan penguasaan iptek yang tersedia.

Pengamatan peneliti pada obyek penelitian yaitu pada Kecamatan Sragen Kabupaten Sragen menunjukkan ada peningkatan. Hal ini disebabkan oleh beberapa faktor yang antara lain menurut pengamatan peneliti yaitu faktor penguasaan iptek, disiplin kerja dan kepuasan kerja. Faktor penguasaan iptek ada peningkatan kualitas yang ditunjukan oleh kemampuan pemimpin dalam meningkatkan kualitas hasil kinerja. Faktor kedisiplinan ada peningkatan yang ditimbulkan dari prestasi daftar hadir scaning sidik jari. Maju dan mundurnya suatu organisasi tidak dapat terlepas dari adanya peran dari pemimpin organisasi. Faktor kepuasan kerja menunjukkan peningkatan semakin terjalinnya kerja sama diantara pegawai maupun pimpinan. Oleh sebab itu pegawai dituntut untuk mampu menyelesaikan tugas dan tanggung jawabnya secara efektif dan efisien.

Faktor berikutnya yang mempengaruhi kinerja pegawai adalah disiplin kerja (Hasibuan, 2017). Disiplin merupakan tindakan manajemen untuk mendorong para anggota organisasi memenuhi tuntutan berbagai ketentuan tersebut Siagian (2017:305). Dalam suatu perusahaan disiplin merupakan suatu bentuk pelatihan yang berusaha memperbaiki dan membentuk pengetahuan, sikap dan prilaku karyawan sehingga para pegawai tersebut secara sukarela berusaha bekerja secara kooperatif dengan para pegawai yang lain dengan meningkatkan prestasi kerjanya.

Pentingnya kedisiplinan pegawai di Kecamatan Sragen Kabupaten Sragen, yaitu dengan adanya sikap disiplin yang tinggi atau tingkat kedisiplinan pegawai akan selalu memotivasi pegawai bekerja dengan baik, hal ini disebabkan karena dengan selalu bersikap disiplin, maka kesalahan pekerjaan yang akan dilakukan akan sangat minim, sehingga akan berdampak pada kinerja yang optimal. Kedisiplinan pada hakekatnya adalah kemampuan seseorang dalam mengendalikan diri dalam bentuk tidak melakukan tindakan yang tidak sesuai dan bertentangan dengan sesuatu yang telah ditetapkan dan melakukan sesuatu yang mendukung dan melindungi sesuatu yang telah diterapkan. 
Hasil penelitian Caryono, (2010), Susanto, (2019) Gama, et.,al (2017), Yunanato (2016), Ernest (2016) menunjukkan terdapat pengaruh yang positif signifikan disiplin kerja terhadap kepuasan kerja. Hasil berbeda dilakukan oleh Laura dan Hidayat, (2016) menunjukkan terdapat pengaruh yang tidak signifikan disiplin kerja terhadap kepuasan. Hal ini diperkuat oleh hasil penelitian Chen dan Colin (2015), menunjukkan terdapat pengaruh yang positif signifikan disiplin kerja terhadap kinerja, sedangkan Ernest (2016) menunjukkan terdapat pengaruh yang positif tidak signifikan disiplin kerja terhadap kinerja. Berdasarkan perbedaan hasil penelitian (research gab) hasil penelitian, maka penelitian ini menganalisis pengaruh disiplin kerja terhadap kepuasan dan kinerja pegawai.

Upaya mempercepat pencapaian tujuan adalah kedisiplinan kerja dalam organisasi dalam rangka koordinasi tugas. Adanya kedisiplinan kerja yang baik antar pegawai dalam pelaksanaan tugas akan mempercepat penanganan pekerjaan secara efektif dan efisien. Kelancaran kedisiplinan kerja diantara sesama pegawai dan kedisiplinan kerja dengan pimpinan akan memberikan kemudahan dalam pelaksanaan tugas dan tanggungjawab masing-masing pegawai maupun tugas yang dilakukan secara tim.

Aspek kepuasan kerja merupakan aspek yang dinilai sebagai aspek ekstrinsik dari organisasi, sejalan dengan konsep kepuasan kerja tersebut, penilaian ini memfokuskan pada masalah yang berkaitan dengan aspek kepuasan kerja dalam peningkatan kinerja pegawai. Hal ini didasarkan pada pemikiran pada prestasi kerja masih dianggap sebagai pemegang peranan penting dalam pemenuhan kepuasan kerja, karena para pegawai yang diliputi rasa tidak puas atas hal yang memperlemah kinerja akan memberikan dampak bagi organisasi yang bersifat negatif. (Siagian: 2017:102).

Berangkat dari suatu permasalahan yang terjadi pada Kecamatan Sragen Kabupaten Sragen dan variabel yang ada dan model penelitian yang belum pernah dilakukan penelitian pada Kecamatan Sragen Kabupaten Sragen. Peneliti ingin mengungkap suatu permasalahan yang ada ditinjau dari variabel yang digunakan. Berdasarkan uraian di atas dan dari fenomena yang ada maka perlu dilakukan penelitian dengan judul: "Pencapaian Penguasaan Iptek dan Disiplin Kerja Dalam Mencapai Kepuasan Kerja Terhadap Kinerja Pegawai Kecamatan Sragen Kabupaten Sragen".

\section{METODE}

Populasi dalam penelitian ini adalah pegawai di Kecamatan Sragen Kabupaten Sragen sejumlah 64 pegawai, sampel diambil dengan sejumlah sampel yaitu 64 responden dengan teknik sensus.

Variabel yang digunakan dalam penelitian ini adalah variabel independen $(\mathrm{X})$, intervening $(\mathrm{X}, \mathrm{Y})$ dan dependen $(\mathrm{Y})$. Adapun yang termasuk variabel independen adalah penguasaan iptek $\left(\mathrm{X}_{1}\right)$ dan disiplin kerja $\left(\mathrm{X}_{2}\right)$. Variabel intervening adalah kepuasan kerja $\left(\mathrm{X}_{3} / \mathrm{Y}_{1}\right)$ dan variabel dependen adalah kinerja $\left(\mathrm{Y} / \mathrm{Y}_{2}\right)$.

Teknik pengambilan sampel dengan menggunakan sampling jenuh atau sensus yaitu semua anggota populasi digunakan sebagai sampel (Sugiyono, 2016;96).

\section{HASIL PENELITIAN}

Hasil Uji Instrument

Tabel 1. Korelasi Item Pertanyaan Terhadap Variabel Penguasaan iptek

\begin{tabular}{|c|c|c|c|}
\hline $\begin{array}{c}\text { Item } \\
\text { Pertanyaan }\end{array}$ & $\mathbf{r}_{\text {item }}$ & $\mathbf{r}_{\text {tabel }}$ & Keterangan \\
\hline X1_1 & 0,628 & 0,242 & Valid \\
\hline X1_2 & 0,488 & 0,242 & Valid \\
\hline X1_3 & 0,623 & 0,242 & Valid \\
\hline X1_4 & 0,759 & 0,242 & Valid \\
\hline X1_5 & 0,759 & 0,242 & Valid \\
\hline
\end{tabular}


Sumber : Data yang diolah, 2022

Tabel 2. Korelasi Item Pertanyaan Terhadap Variabel Disiplin kerja

\begin{tabular}{|c|c|c|c|}
\hline $\begin{array}{c}\text { Item } \\
\text { Pertanyaan }\end{array}$ & $\mathbf{r}_{\text {item }}$ & $\mathbf{r}_{\text {tabel }}$ & Keterangan \\
\hline X2_1 & 0,434 & 0,242 & Valid \\
\hline X2_2 & 0,718 & 0,242 & Valid \\
\hline X2_3 & 0,718 & 0,242 & Valid \\
\hline X2_4 & 0,462 & 0,242 & Valid \\
\hline X2_5 & 0,480 & 0,242 & Valid \\
\hline
\end{tabular}

Sumber : Data yang diolah, 2022

Tabel 3. Korelasi Item Pertanyaan Terhadap Variabel Kepuasan kerja

\begin{tabular}{|c|c|c|c|}
\hline Item Pertanyaan & ritem & rtabel & Keterangan \\
\hline X3_1 & 0,416 & 0,242 & Valid \\
\hline X3_2 & 0,510 & 0,242 & Valid \\
\hline X3_3 & 0,575 & 0,242 & Valid \\
\hline X3_4 & 0,598 & 0,242 & Valid \\
\hline X3_5 & 0,673 & 0,242 & Valid \\
\hline
\end{tabular}

Sumber : Data yang diolah, 2022

Tabel 4. Korelasi Item Pertanyaan Terhadap Variabel Kinerja

\begin{tabular}{|c|c|c|c|}
\hline $\begin{array}{r}\text { Item } \\
\text { Pertanyaan }\end{array}$ & $\mathbf{r}_{\text {item }}$ & $\mathbf{r}_{\text {tabel }}$ & Keterangan \\
\hline Y_1 & 0,683 & 0,242 & Valid \\
\hline Y_2 & 0,549 & 0,242 & Valid \\
\hline Y_3 & 0,568 & 0,242 & Valid \\
\hline Y_4 & 0,609 & 0,242 & Valid \\
\hline Y_5 & 0,525 & 0,242 & Valid \\
\hline
\end{tabular}

Sumber : Data yang diolah, 2022

Tabel 5. Hasil Uji Reliabilitas

\begin{tabular}{|l|c|c|c|}
\hline \multicolumn{1}{|c|}{ Variabel } & $\begin{array}{c}\text { Alpha } \\
\text { Cronbach }\end{array}$ & Kriteria & Keterangan \\
\hline Penguasaan iptek & 0,841 & Alpha & Reliabel \\
Disiplin kerja & 0,779 & Cronbach & Reliabel \\
Kepuasan kerja & 0,774 & $>0,60$ & Reliabel \\
Kinerja & 0,794 & maka & Reliabel \\
& & reliabel & \\
\hline
\end{tabular}

Sumber : Data yang diolah, 2022

Tabel 6. Hasil Analisis Jalur Persamaan 1

Coefficients $^{\mathrm{a}}$

\begin{tabular}{|c|c|c|c|c|c|c|}
\hline \multirow[b]{2}{*}{ Model } & & \multicolumn{2}{|c|}{$\begin{array}{l}\text { Unstandardized } \\
\text { Coefficients }\end{array}$} & \multirow{2}{*}{$\begin{array}{c}\begin{array}{c}\text { Standardized } \\
\text { Coefficients }\end{array} \\
\text { Beta }\end{array}$} & \multirow[b]{2}{*}{ t } & \multirow[b]{2}{*}{ Sig. } \\
\hline & & $B$ & Std. Error & & & \\
\hline \multirow[t]{3}{*}{1} & (Constant) & 1,542 & 1,307 & & 1,180 & ,243 \\
\hline & Penguasaan IPTEK & 025 & ,077 & 027 & ,327 & ,745 \\
\hline & Disiplin Kerja &, 890 &, 084 & 879 & 10,544 & ,000 \\
\hline
\end{tabular}

a. Dependent Variable: Kepuasan Kerja

Sumber : Data yang diolah, 2022 


\section{Tabel 7. Hasil Analisis Jalur Persamaan 2}

\begin{tabular}{|c|c|c|c|c|c|c|}
\hline \multicolumn{7}{|c|}{ Coefficients } \\
\hline \multirow[b]{2}{*}{ Model } & & \multicolumn{2}{|c|}{$\begin{array}{l}\text { Unstandardized } \\
\text { Coefficients }\end{array}$} & \multirow{2}{*}{$\begin{array}{c}\text { Standardized } \\
\text { Coefficients } \\
\text { Beta } \\
\end{array}$} & \multirow[b]{2}{*}{$t$} & \multirow[b]{2}{*}{ Sig. } \\
\hline & & B & Std. Error & & & \\
\hline 1 & (Constant) & $-2,151$ & ,791 & & $-2,721$ & 009 \\
\hline & Penguasaan IPTEK & ,271 & ,046 & ,273 & 5,849 & ,000 \\
\hline & Disiplin Kerja & 052 & ,085 & ,048 &, 616 &, 540 \\
\hline & Kepuasan Kerja & ,770 & ,077 & ,719 & 10,056 & ,000 \\
\hline
\end{tabular}

a. Dependent Variable: Kinerja

Sumber : Data yang diolah, 2022

\section{Tabel 8. Hasil Uji F}

ANOVA

\begin{tabular}{|c|c|c|c|c|c|c|}
\hline Model & & $\begin{array}{l}\text { Sum of } \\
\text { Squares }\end{array}$ & $d f$ & Mean Square & $\mathrm{F}$ & Sig. \\
\hline \multirow[t]{3}{*}{$\overline{1}$} & Regression & 220,290 & 3 & 73,430 & 322,834 &, $000^{a}$ \\
\hline & Residual & 13,647 & 60 & ,227 & & \\
\hline & Total & 233,937 & 63 & & & \\
\hline
\end{tabular}

a. Predictors: (Constant), Kepuasan Kerja, Penguasaan IPTEK, Disiplin Kerja

b. Dependent Variable: Kinerja

Sumber : Data yang diolah, 2022

Tabel 9. Hasil Koefisien Determinasi Persamaan 1

Model Summary

\begin{tabular}{|l|r|r|r|r|}
\hline Model & \multicolumn{1}{|c|}{$\mathrm{R}$} & R Square & $\begin{array}{c}\text { Adjusted } \\
\text { R Square }\end{array}$ & $\begin{array}{r}\text { Std. Error of } \\
\text { the Estimate }\end{array}$ \\
\hline 1 &, $900^{\mathrm{a}}$ &, 810 &, 803 &, 797 \\
\hline
\end{tabular}

a. Predictors: (Constant), Disiplin Kerja, Penguasaan IPTEK

Sumber : Data yang diolah, 2022

Tabel 10. Hasil Koefisien Determinasi Persamaan 2

Model Summary

\begin{tabular}{|l|r|r|r|r|}
\hline Model & \multicolumn{1}{|c|}{$\mathrm{R}$} & R Square & $\begin{array}{r}\text { Adjusted } \\
\text { R Square }\end{array}$ & $\begin{array}{r}\text { Std. Error of } \\
\text { the Estimate }\end{array}$ \\
\hline 1 &, $970^{\mathrm{a}}$ &, 942 &, 939 &, 477 \\
\hline
\end{tabular}

a. Predictors: (Constant), Kepuasan Kerja, Penguasaan IPTEK, Disiplin Kerja

b. Dependent Variable: Kinerja

Sumber : Data yang diolah, 2022 
Tabel 11. Hasil Analisis Koefisien Korelasi

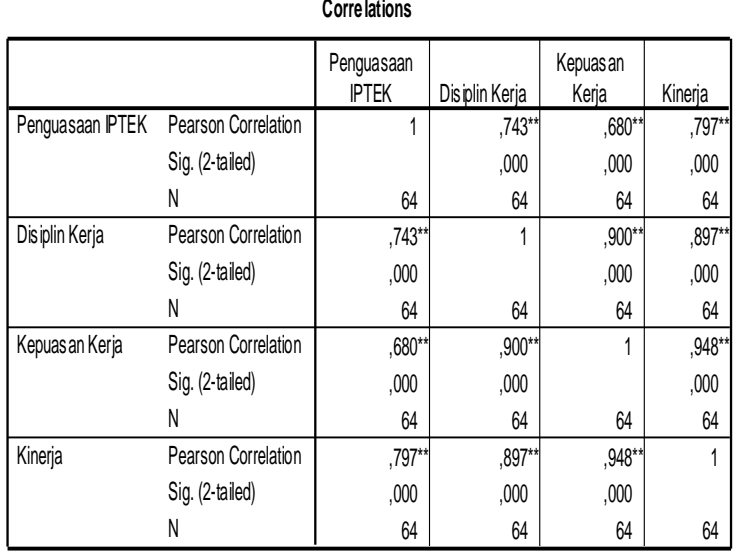

${ }^{* *}$. Correlation is significant at the 0.01 level (2-tailed).

Sumber : Data yang diolah, 2022

Tabel 12. Pengaruh Langsung, Pengaruh Tidak Langsung dan Total Pengaruh

\begin{tabular}{|c|c|c|c|}
\hline \multirow[b]{2}{*}{ Dari Variabel } & \multicolumn{2}{|c|}{ Koefisien Jalur } & \multirow[b]{2}{*}{$\begin{array}{c}\text { Total } \\
\text { Pengaruh }\end{array}$} \\
\hline & $\begin{array}{c}\mathrm{DE} \\
\text { (Direct } \\
\text { Effect) }\end{array}$ & $\begin{array}{c}\mathrm{IE} \\
\text { (Indirect } \\
\text { Effect) }\end{array}$ & \\
\hline $\mathrm{X}_{1}$ ke $\mathrm{Y}$ & $\mathrm{P}_{3}=0,273$ & & \\
\hline $\mathrm{X}_{2}$ ke $\mathrm{Y}$ & $\mathrm{P}_{4}=0,048$ & & \\
\hline $\begin{array}{c}\mathrm{X}_{1} \text { melalui }_{\mathrm{X}} \\
\mathrm{Ke} \mathrm{Y}\end{array}$ & & $\begin{array}{l}=\mathrm{P}_{1} \times \mathrm{P}_{5} \\
=\quad 0,027 \\
0,719 \\
=0,019\end{array}$ & $\begin{array}{l}=\mathrm{P}_{3}+\left(\mathrm{P}_{1} \times \mathrm{P}_{5}\right) \\
=0,273 \\
0,019 \\
=0,292\end{array}$ \\
\hline $\begin{array}{c}\mathrm{X}_{2} \text { melalui } \mathrm{X}_{3} \\
\mathrm{Ke} \mathrm{Y}\end{array}$ & & $\begin{array}{l}=\mathrm{P}_{2} \times \mathrm{P}_{5} \\
=\quad 0,879 \\
0,719 \\
=0,632\end{array}$ & $\begin{array}{l}=\mathrm{P}_{4}+\left(\mathrm{P}_{2} \times \mathrm{P}_{5}\right) \\
=0,048 \\
0,632 \\
=0,68\end{array}+$ \\
\hline
\end{tabular}

Sumber: Data diolah, 2022

Tabel di atas hubungan antar variabel dapat digambarkan dengan bagan sebagai berikut:

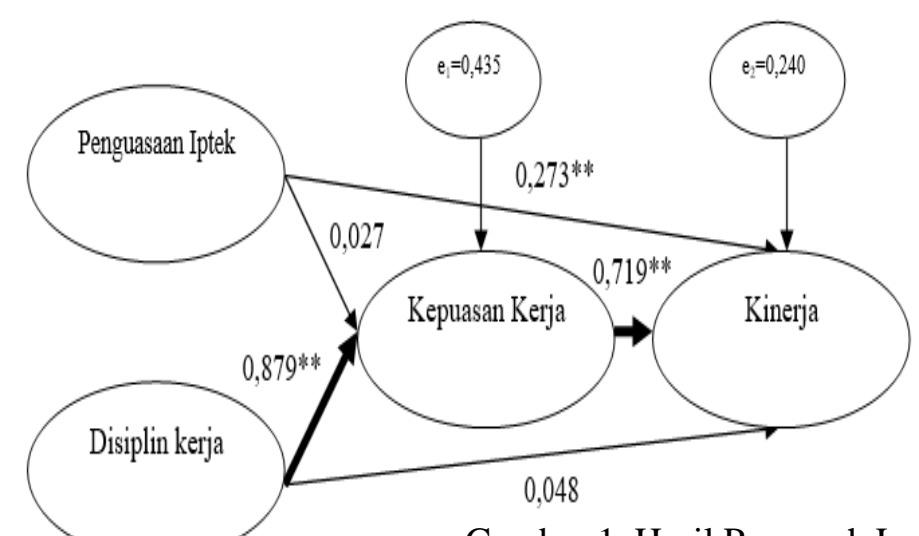

Gambar 1. Hasil Pengaruh Langsung Dan Tidak Langsung 


\section{PEMBAHASAN}

1. Pengaruh Penguasaan iptek Terhadap Kinerja Melalui Kepuasan Kerja

Berdasarkan hasil analisis jalur, pengaruh langsung penguasaan iptek terhadap kinerja lebih besar nilai koefisiennya dibandingakan pengaruh tidak langsung penguasaan iptek terhadap kinerja melalui kepuasan kerja, sehingga jalur langsung efektif untuk meningkatkan kinerja. Hasil peneliitian ini mendukung dengan temuan penelitian yang dilakukan oleh Pandapotan, (2019), Wulandari, (2016), Zahara dan Hidayat, (2017), Caryono, (2010), Susanto, (2019) Gama, et., al (2017), Yunanato (2016), Ernest (2016), Laura dan Hidayat, (2016), Chen dan Colin (2015) hasil penelitiannya menunjukkan bahwa penguasaan iptek berpengaruh signifikan terhadap kinerja.

Penggunaan variabel intervening kepuasan kerja dalam rangka peningkatan kinerja, untuk variabel penguasaan iptek adalah tidak efektif, karena pengaruh tidak langsung lebih kecil dibandingkan pengaruh langsung. Sehingga upaya untuk meningkatkan penguasaan iptek untuk meningkatkan kepuasan kerja tidak efektif, dan peningkatan kepuasan kerja terhadap kinerja Kecamatan Sragen Kabupaten Sragen efektif. Hal yang perlu dilakukan untuk meningkatkan penguasaan iptek adalah dengan cara:

Meningkatkan penguasaan iptek untuk meningkatkan kinerja pegawai. Hal ini dapat dilakukan dengan cara:

a. Dengan kemajuan teknologi terciptalah metode-metode baru yang membuat pegawai mampu memahami materi-materi yang susah dimengerti.

b. Perkembangan IPTEK akan sangat serasi apabila diikuti dengan meningkatnya daya kemampuan masyarakat dalam menyerap dan menerapkan IPTEK tersebut.

c. Perkembangan IPTEK akan sangat serasi apabila diikuti dengan meningkatnya daya kemampuan masyarakat dalam menyerap dan menerapkan IPTEK tersebut.

2. Pengaruh Disiplin kerja Terhadap Kinerja melalui kepuasan kerja

Dari analisis jalur bahwa jalur langsung pengaruh disiplin kerja terhadap kinerja lebih kecil dibandingkan pengaruh tidak langsung disiplin kerja terhadap kinerja melalui kepuasan kerja, hal ini berarti, untuk meningkatkan kinerja Pegawai di Kecamatan Sragen Kabupaten Sragen sebaiknya menggunakan variabel intervening kepuasan kerja. Hal ini didukung dengan hasil uji t yang menyatakan bahwa kepuasan kerja berpengaruh terhadap kinerja pegawai.

Temuan ini mendukung hasil penelitian yang dilakukan oleh Pandapotan, (2019), Wulandari, (2016), Zahara dan Hidayat, (2017), Caryono, (2010), Susanto, (2019) Gama, et.,al (2017), Yunanato (2016), Ernest (2016), hasil penelitiannya menunjukkan bahwa kepuasan kerja berpengaruh signifikan terhadap kinerja.

Penggunaan variabel intervening kepuasan kerja dalam rangka peningkatan kinerja, untuk variabel disiplin kerja adalah efektif. Dalam analisis ini maka jalur tidak langsung disiplin kerja terhadap kinerja melalui kepuasan kerja adalah efektif, langkah-langkah yang perlu dilakukan untuk meningkatkan kinerja melalui peningkatan kepuasan kerja adalah dengan cara:

a. Meningkatkan promosi jabatan yang diberikan kepada pegawai yang berprestasi.

b. Meningkatkan sarana dan prasarana yang ada.

c. Meningkatkan hubungan yang baik dengan rekan kerja di kantor 


\section{Kesimpulan}

1. Hasil Uji Hipotesis adalah:

a. Penguasaan iptek berpengaruh tidak signifikan terhadap kepuasan kerja. Hipotesis 1 tidak terbukti.

b. Disiplin kerja berpengaruh signifikan terhadap kepuasan kerja. Hipotesis 2 terbukti.

c. Penguasaan iptek berpengaruh signifikan terhadap kinerja pegawai. Hipotesis 3 terbukti.

d. Disiplin kerja berpengaruh tidak signifikan terhadap kinerja pegawai. Hipotesis 4 terbukti.

e. Kepuasan kerja berpengaruh signifikan terhadap kinerja pegawai. Hipotesis 5 terbukti.

2. Hasil uji $F$ diketahui besarnya nilai $F=322,834$ signifikansi $0,000<0,05$. Sehingga dapat disimpulkan secara bersama-sama penguasaan iptek, disiplin kerja dan kepuasan kerja berpengaruh signifikan terhadap kinerja pegawai Kecamatan Sragen Kabupaten Sragen.

3. Nilai $\mathrm{R}^{2}$ total sebesar 0,989 dapat diartikan variasi kinerja pegawai di Kecamatan Sragen Kabupaten Sragen dijelaskan oleh variabel penguasaan iptek, disiplin kerja dan kepuasan kerja, sebesar $98,9 \%$ dan sisanya $1,1 \%$ dijelaskan variabel lain diluar model penelitian sebagai contoh iklim organisasi dan pengawasan.

4. Hasil analisis jalur diketahui jalur tidak langsung disiplin kerja terhadap kinerja melalui kepuasan kerja, merupakan jalur yang dominan atau efektif untuk meningkatkan kinerja pegawai di Kecamatan Sragen Kabupaten Sragen.

\section{Saran dan Rekomendasi}

Berdasarkan hasil penelitian disarankan hal-hal sebagai berikut:

1. Variabel kepuasan kerja berpengaruh signifikan terhadap kinerja, untuk itu sebaiknya dalam meningkatkan kinerja pegawai Kecamatan Sragen Kabupaten Sragen, perlu meningkatkan kepuasan kerja yang lebih optimal kembali. Hal ini dapat ditingkatkan dengan cara:

a. Meningkatkan promosi jabatan yang diberikan kepada pegawai yang berprestasi.

b. Meningkatkan sarana dan prasarana yang ada.

c. Meningkatkan hubungan yang baik dengan rekan kerja di kantor.

2. Variabel penguasaan iptek perlu ditingkatkan lagi agar kinerja lebih optimal, hal yang perlu ditingkatkan dalam meningkatkan penguasaan iptek antara lain:

a. Dengan kemajuan teknologi terciptalah metode-metode baru yang membuat pegawai mampu memahami materi-materi yang susah dimengerti.

b. Perkembangan IPTEK akan sangat serasi apabila diikuti dengan meningkatnya daya kemampuan masyarakat dalam menyerap dan menerapkan IPTEK tersebut.

c. Perkembangan IPTEK akan sangat serasi apabila diikuti dengan meningkatnya daya kemampuan masyarakat dalam menyerap dan menerapkan IPTEK tersebut.

3. Bagi peneliti yang akan datang hendaknya dapat menambah sampel penelitian agar hasilnya lebih maksimal ataupun dapat menambahkan variabel-variabel lain yang dapat meningkatkan kinerja pegawai.

\section{DAFTAR PUSTAKA}

Allyssa, Laura dan Hidayat, (2016). Analisis Pengaruh Budaya Organisasi Dan Kepemimpinan Terhadap Kepuasan Kerja Pegawai Serta Dampaknya Terhadap Kinerja Pegawai PT.Asuransi Astra Buana. Jurnal Manajemen Universitas Mercubuana Yoyyakarta. V. 6. No. 3 Hal. 13-26 
Caryono, 2010. Pengaruh Disiplin Kerja, Motivasi, Budaya Organisasi Dan Stres Kerja Terhadap Kepuasan Kerja Guru Pada Slta Di Bawah Yayasan Muhammadiyah Se Kabupaten Purworejo. Jurnal Bisnis Teori dan Implementasi Vol.1, No.1, Februari 2010| JBTI

Davis S., 2014, Managing Corporate Culture, Cambridge, MA: Belinger

Djarwanto dan Subagyo, Pangestu, 2019: Statistik Induktif, Edisi: 4, Yogyakarta: BPFE

Fajar Purnomo, (2014). Pengaruh Kepemimpinan, Motivasi, Dan Disiplin Kerja Terhadap Kepuasan dan Kinerja Karyawan PDAM Tirta Moedal Semarang. Jurnal Manajemen Bisnis UNNES Semarang Vol.3 No.1 2014

Fuad mas'ud. 2014, "Survai Diagnosis Organisasional”,Badan penerbit Universitas Diponegoro, Semarang.

Ghozali Imam, 2015. Analisis Multivariate dengan program SPSS. Semarang: Badan Penerbit Universitas Diponegoro.

Gibson, James L, John M Ivancevich. 2014, Organisasi dan Manajemen: Perilaku, Struktur, Proses, Edisi 4, Terjemahan. Jakarta: Erlangga.

Gujarati, Damodar. 2015. Ekonometrika Dasar. Erlangga. Jakarta

Haryanto, A. T., \& Dewi, S. N. (2020). Peran Kepemimpinan Efektif dan Kedisiplinan Terhadap Komitmen Organisasi dan Motivasi Maslow Pada Kinerja Tugas Guru di Sekolah Dasar. Jurnal Basicedu, 4(4), 801-812.

Kuntoro, 2016, Pengaruh Pendidikan pelatihan, lingkungan kerja terhadap kepuasan kerja dan kinerja pegawai PT Carita Boat Yogyakarta, Jurnal Manajemen Universitas Mercubuana Yoyyakarta. V. 7. No. 3 Hal. 13-26.

Moenir, 2014. Metodologi Penelitian,

Nuryanti \& Sintasiih, 2020. Kepuasan Kerja Dan Komitmen Organisasional Berpengaruh Terhadap Kinerja Karyawan. E-Jurnal Manajemen, Vol. 9, No. 3, 2020 : 926-947 ISSN : 2302-8912 DOI: https://doi.org/10.24843/EJMUNUD.2020.v09.i03.p06

Pandapotan, 2019. Pengaruh Disiplin Kerja Dan Penguasaan Teknologi Informasi Terhadap Kinerja Pegawai Di Universitas Darma Agung. Jurnal Darma Agung Volume XXVII, Nomor 1, April 2019: $785-796$

Peraturan Pemerintah (PP) Nomor 53 tahun 2015 tentang peraturan disiplin Pegawai Negeri Sipil, Jakarta

Peraturan Pemerintah (PP) Republik Indonesia, 2016, Undang-undang Republik Indonesia Nomor 46 Tahun 2016 tentang Penilaian Kinerja Pegawai, Jakarta

Ridwan, 2015, Skala pengukuran Variabel-Variabel Penelitian, Cetakan Ketiga, Alfabeta, Bandung.

Robbins S. P.,2014, Perilaku Organisasi : Konsep, Kontroversi, Aplikasi, edisi kedelapan versi Bahasa Indonesia, Jilid 12, PT Prenhallindo, Jakarta.

Robbins Stephen dan Coulter Mary. 2016. Manajemen. Jakarta: Indexs.

Sarwono, Jonathan. 2015. Analisis Jalur Untuk Bisnis dengan SPSS. Penerbit Andi Offset:Yogyakarta. 
Schein E., 2014, Organizational Culture and Leadership, San Frasisco Jossey Bass.

Siagian, S.P. 2017, Teori Motivasi dan Aplikasinya, Jakarta :Rineka Cipta. Pp.102-106.

Simamora, Henry. 2014. Manajemen Sumber Daya Manusia. Edisi kedua Sekolah Tinggi Ilmu Ekonomi (YKPN). Yogyakarta.

Siswanto, 2013, Riset Sumber Daya Manusia, Jakarta:PT. Gramedia Pustaka Utama

Stoner, James A.F, 2017. Management, Third Edition. Prentice-Hall International Inc.Englewood.Chlips.New Jersey

Sugiyono, 2019. Metode Penelitian Bisnis. Bandung. Alfabeta.

Susanto. 2019. Pengaruh Motivasi Kerja, Kepuasan Kerja, Dan Disiplin Kerja Terhadap Kinerja Karyawan Pada Divisi Penjualan PT Rembaka. AGORA Vol. 7, No. 1 (2019)

Timpe, D.A. 2017. Produktivitas: Seri Manjemen Sumber Daya Manusia. Jakarta:Alex Media Komputindo.

Wulandari, 2016. Pengaruh Budaya Organisasi, Disiplin Kerja, Serta Gaya Kepemimpinan Terhadap Kinerja Karyawan Agroteknopark Kabupaten Ogan ILIR. Muqtashid, Vol. I, No. O1, Edisi Maret 2016

Yoti Gama, Pradanawati \& Hidayat, (2017). Pengaruh Kompensasi dan disiplin kerja terhadap kinerja karyawan dengan motivasi sebagai variabel intervening pada Perum Perhutani Unit 1 Jawa Tengah. Jurnal Bisnis dan Manajemen Vol. 4 No. 4 Pp. 56-68

Yukl, Gary. 2015. Pendidikan pelatihan dalam Organisasi. Edisi Kelima. PT. Indeks, Jakarta.

Zahara dan Hidayat, 2017. Pengaruh Kepuasan Dan Disiplin Kerja Terhadap Kinerja Karyawan Bank Di Kota Batam. Journal Of Applied Managerial Accounting Vol. 1, No. 2, 2017, 150-156 ISSN: 2548-9917 (online version) 